\title{
BMJ Open Patients' perception of the outpatient pharmaceutical service quality in hospital pharmacies with auditable pharmaceutical transactions and services in Ethiopia: a cross-sectional study
}

To cite: Kassa DG, Xiang C, Hu S, et al. Patients' perception of the outpatient pharmaceutical service quality in hospital pharmacies with auditable pharmaceutical transactions and services in Ethiopia: a crosssectional study. BMJ Open 2021;11:e042853. doi:10.1136/ bmjopen-2020-042853

- Prepublication history for this paper is available online. To view these files, please visit the journal online (http://dx.doi org/10.1136/bmjopen-2020042853).

Received 21 July 2020

Revised 16 December 2020

Accepted 18 March 2021

A) Check for updates

(c) Author(s) (or their employer(s)) 2021. Re-use permitted under CC BY-NC. No commercial re-use. See rights and permissions. Published by BMJ.

${ }^{1}$ Department of Pharmacy Administration and Clinical Pharmacy, School of Pharmacy, Xi'an Jiaotong University, Xi'an, China

${ }^{2}$ Center for Drug Safety and Policy Research, Xi'an Jiaotong University, Xi'an, China ${ }^{3}$ Department of Epidemiology and Health Statistics, Xi'an Jiaotong University, Xi'an, China

Correspondence to

Dr Caijun Yang;

yangcj@xjtu.edu.cn

\section{ABSTRACT}

Objective To ensure the availability of quality pharmaceutical products and effective pharmaceutical services, a package of interventions named auditable pharmaceutical transactions and services (APTS), was implemented in the tertiary and secondary hospitals across Ethiopia since 2014. This study aimed to evaluate outpatients' perception of pharmaceutical service quality in hospitals with APTS in Ethiopia.

Design Cross-sectional study.

Setting Seven hospitals of Tigray, Ethiopia.

Participants 794 patients coming for pharmaceutical services.

Main outcome measures SERVQUAL instrument was employed to collect the patient's perception of pharmaceutical services. The mean perception score of pharmaceutical service quality was the main outcome measurement.

Results Out of 810 patients approached, 794 participated in the study (response rate of 98.02\%). Overall, the mean perception score of the service quality was 3.1 of 5 . Among the five dimensions of SERVQUAL, dimension of empathy achieved the highest result with a mean score of 3.71 , and tangibility was the second (3.19), followed by responsiveness (3.08), assurance (2.87) and reliability (2.81). The perception of patients in tertiary hospitals of service quality was more positive compared with patients in secondary hospitals $(3.265>3.011, p=0.04)$. However, the difference was only significant in the dimension of assurance when considering the five dimensions separately. Respondents who were older, widowed, illiterate, farmer, retired or Orthodox were found to have better quality service experience compared with others $(p=0.001)$.

Conclusion Generally, outpatients' perception of pharmaceutical service quality was positive. However, two dimensions of the service quality (assurance and reliability) were negatively perceived. To improve the service quality, we recommended the following: (1) managers should provide more training for pharmacists to strengthen their professional knowledge and encourage them to cooperate with other professionals; (2) the government needs to develop guidelines on information provided to patients

\section{Strengths and limitations of this study}

- This is the first study investigating the quality of pharmaceutical service after auditable pharmaceutical transactions and services (APTS), which has seen that the perception of most patients toward the outpatient pharmaceutical service quality in hospitals with APTS was positive.

- Two dimensions of service quality, including assurance and reliability, were negatively perceived. This result provides strategies to the Ethiopian government to improve the pharmaceutical service quality via providing more training for pharmacists to enrich their knowledge, and encouraging them to cooperate with other professionals.

- The generalisability of the results might be limited since it was only conducted in one region of Ethiopia. However, the sample size of this survey was reasonably large, and respondents with different demographic and socioeconomic features were sampled, which might help display the actual picture in Tigray.

and train the pharmacists to follow them; (3) hospitals can apply various procurement methods and efficient inventory management methods.

\section{INTRODUCTION}

Pharmaceutical service is defined as the pharmacist's contribution to the care of individuals to optimise medicine use and improve health outcomes. ${ }^{1} \quad$ Suboptimal pharmaceutical service may lead to inappropriate treatment with medication, prolongation or exacerbation of the disease, and an increase in the cost of treatment. ${ }^{2}$ The pharmaceutical service in Ethiopia has been criticised for the poor availability of pharmaceutical products and low quality of pharmacy service. A national assessment of the pharmaceutical sector in 
Ethiopia in 2003 showed that the average duration of drugs in shortage in public health facilities was 99.2 days and the expiration rate was $8.24 \% .^{23}$ The availability of essential medicines at the dispensaries of 17 government hospitals at the time of visit ranged from $33.3 \%$ to $100 \%{ }^{4}$ The average counselling time per patient was only $14.93 \mathrm{~s}$, while the standard duration set by the government was 15 min. ${ }^{45}$ In Ethiopia, only $50 \%$ of patients knew how to take their medicines properly. ${ }^{6}$

As there was no document recording the pharmaceuticals with costs received to each hospital, or medicines issued to dispensing outlets or dispensed to end users, expired or lost, the type, quantity and price of medicines that are transacted had not been traced. ${ }^{7}$ Lack of transparency and accountability in managing medicines and service transactions in health facilities was regarded to contribute to most of those pharmaceutical issues. To tackle those challenges, Ethiopia started to implement a new model of pharmaceutical transactions called the auditable pharmaceutical transactions and services (APTS) in its tertiary and secondary hospitals since $2014 .^{8}$ APTS brought a major change to hospital pharmacies in five aspects: (1) reorganising the dispensing units; (2) aiding to use pharmaceutical budget efficiently; (3) auditing pharmaceutical services and transactions; (4) assisting in determining accurate dispenser's deployment, performance monitoring and on-the-job training; and (5) coding for medical products to ensure the traceability of medicines and transactions at any point. ${ }^{7}$ The ultimate goal of APTS was to improve the availability of medicines, logically sequence multiple counters and staff members, streamline patients' flow, provide better medicine counselling services, reduce waiting time, and finally provide quality pharmaceutical services and satisfy patients.

It has been 5 years since the implementation of APTS in Ethiopia. However, to the best of our knowledge, few published data addressed the quality of pharmaceutical service after APTS. Most reports and papers described the quality of health, ${ }^{910}$ and only one research explored the extent and reasons for dissatisfaction of outpatients with pharmacy services, at two hospitals with APTS (those hospitals have implemented APTS) in 2016 in Harar, eastern Ethiopia. ${ }^{11}$ Their research mainly focused on the pharmacists' service, such as the clearness of pharmacists' voice and tone, politeness of pharmacists, the sufficiency of pharmacists' knowledge, etc. Pharmacists' performance was a critical factor of the service quality of pharmacy, but it did not equate to the whole pharmaceutical service. Pharmaceutical service is multifaceted and can be affected by technical, interpersonal and environmental components, such as waiting area, waiting time, medicine availability, etc.

In the hospitals with APTS in Ethiopia, the outpatient pharmacy organised the dispensing set-up as the prescription evaluator and biller, cashier and counsellor (separate cubicles for evaluator, cashier and counsellor). ${ }^{7}$ Therefore, the pharmaceutical service for an outpatient in Ethiopia started from the moment he/she entered the outpatient pharmacy until he/she left it, included waiting, paying, getting medicines, being provided information about how to take and storage of medicines, and possible side effects of medicines.

In this study, we assessed the outpatients' perception of the pharmaceutical service of hospitals with APTS. Using a mature service quality model of SERVQUAL, we can find out the whole level of patients' understanding of pharmaceutical service quality in hospitals with APTS, and which dimension of quality had a higher or lower perception. In addition, the relationship between patients' demographic characteristics and their perception can also be generated. Currently, the government of Ethiopia planned to expand the APTS to primary hospitals. We believe our study will help to highlight potential interventions for improving the quality of pharmaceutical services in hospitals and can also help the expansion of APTS smoothly.

\section{MATERIALS AND METHODS}

\section{Study setting, design and participants}

We conducted the study in Tigray, a region of northern Ethiopia. Tigray covered an area of $53638 \mathrm{~km}^{2}$ and had a total population of 5.3 million, ranked ninth for gross domestic product per capita in Ethiopia (nine main regions and two city administrations in total) in 2017. There are six rural and one urban administrations in this region. The main ethnic group is Tigri, accounting for $96.55 \%$ of the local population. There are three predominant religions: Orthodox, Muslim and Catholic.

In Tigray, there are 14 secondary and 2 tertiary hospitals in total (table 1). We selected one tertiary and six secondary hospitals for study by a stratified cluster random sampling method to represent each subregion adequately based on their geographical and population characteristics. ${ }^{12}$ All these hospitals have implemented APTS since 2014.

The study was conducted in the outpatient pharmacies of the seven hospitals. Patients coming for pharmaceutical service were randomly selected and interviewed. The exclusion criteria were the following: (1) patients were critically ill, comatose or psychiatric with compromised cognitive function; (2) people aged below 18 years; (3) those who were unwilling to participate. For each level of

Table 1 Number of selected hospitals and comparative characteristics of Tigray and the whole country, Ethiopia, 2017

\begin{tabular}{|c|c|c|c|}
\hline Characteristic & Ethiopia & Tigray & $\begin{array}{l}\text { Number of } \\
\text { selected } \\
\text { hospitals }\end{array}$ \\
\hline Population & 106399924 & 5247005 & \\
\hline Tertiary hospitals & 33 & 2 & 1 \\
\hline $\begin{array}{l}\text { Secondary } \\
\text { hospitals }\end{array}$ & 116 & 14 & 6 \\
\hline
\end{tabular}


hospital, the sample size of participants was determined using the following formula: $\left[\mathrm{N}=\left(\mathrm{Z}_{1-\alpha}\right)^{2} \times \sigma^{2} / \mathrm{SE}^{2}\right]$. The $\mathrm{SD}$ $(\sigma)$ of mean satisfaction level was considered as 0.5 . The margin of error (SE) was set to be 0.05 , with a $95 \%$ CI. With an added contingency of $5 \%$ for non-response and inappropriate responses, the final sample was calculated to be 405 for each level of hospitals, and a total of 810 .

\section{Data instrument}

As a valid, reliable and flexible instrument measuring service quality, ${ }^{13}$ the SERVQUAL questionnaire has been widely applied to measure performance in the service industries, including medical services at hospitals. ${ }^{14}{ }^{15}$ SERVQUAL includes five dimensions of service ${ }^{16}{ }^{17}$ : (1) tangibility: physical facilities, equipment and appearance of personnel; (2) reliability: ability to perform the promised service with reliability and accuracy; (3) responsiveness: willingness to help customers and provide prompt service; (4) assurance: knowledge and courtesy of employees and their ability to inspire trust and confidence; (5) empathy: caring, individualised attention provided to customers. ${ }^{15}$

Data were collected through a face-to-face interview using a semistructured questionnaire containing 23 questions of SERVQUAL, adapted from previous studies, ${ }^{18-20}$ and 13 questions for collecting sociodemographic characteristics of patients. A 5-point Likert scale ranging from 'strongly disagree' (1) to 'strongly agree' (5) was used to measure patients' perception of service quality.

The questionnaire was designed in English initially and then translated into the local language (Amharic and Tigrigna) by a team of bilingual experts, and then retranslated into English to ensure the consistency. To optimise the clarity of the language and questionnaire structure, a pilot study was conducted among 35 outpatients in a hospital pharmacy, which was not selected for the final study.

\section{Data collection}

Seven research assistants were recruited for collecting the data and were given extensive training by the principal investigator (PI). The main contents of training include: (1) explaining the study purpose to patients; (2) dealing with difficulties during the data collection, for example, help illiterate patients understand each item and select their responses according to available answers. After training, all the research assistants were allocated to different hospitals to collect data. The PI carried out spot investigations to ensure data quality.

During data collection, the patients were provided with an introduction about the study purpose before answering questionnaires. The questionnaire took $5-10 \mathrm{~min}$ to complete. A gift of 20 Ethiopian birr was provided to the patient who completed the survey as an incentive.

\section{Data management and analysis}

Data were compiled in Microsoft Excel and analysed using SPSS V.19.0. Descriptive statistical analysis was used to summarise the sociodemographic characteristics of the participants. T-test and one-way analysis of variance were employed to explore the associations between sociodemographic variables and quality perceptions. A $p$ value of $<0.05$ was considered as statistically significant.

\section{Patient and public involvement}

A team of bilingual experts were included in the translation of the questionnaire and local language. Patients were included in the data collection. Patients or the public were not directly involved in the design and conception of the study nor the analysis or interpretation of the results.

\section{RESULTS \\ Sociodemographic characteristics}

Out of 810 patients approached, 794 adult patients agreed to participate, giving a response rate of $98.02 \%$. Of these, more than half $(\mathrm{n}=434 ; 54.87 \%)$ of the participants were male, and the largest age group was 30-39 years $(\mathrm{n}=265 ; 33.4 \%)$. A similar number of both urban and rural patients (urban 401;50.5\%) participated in the study. Most participants came from the ethnic group of Tigri $(\mathrm{n}=653 ; 82.2 \%)$ and religion group of Orthodox $(\mathrm{n}=650 ; 81.9 \%)$. There were $26.3 \%$ of participants who were either illiterate or had a high school education. Table 2 shows the complete demographic picture of all the participants.

\section{Service quality}

Questionnaire items were tested and validated before the commencement of the study. To validate the internal consistency and reliability of the questionnaire, Cronbach's alpha of the questions for service quality was assessed. As shown in table 3, Cronbach's alpha ranged from 0.746 to 0.771 for the five service quality dimensions and a total scale of 0.877 , giving an acceptable level of reliability. ${ }^{21}$

Table 4 presents the mean score and SD for each statement. The overall perception of the service quality was 3.1. For the five quality dimensions, the dimension of empathy was most positively perceived (3.71), and the dimension of reliability was the least perceived (2.81). Considering each statement, E3 (the privacy) got the highest quality perception (3.83), and A6 (explained possible side effects) had the lowest quality perception (1.80).

Table 5 shows the difference in outpatients' perception of the service quality of different types of hospitals. Overall, patients had a significantly better perception of the quality of pharmaceutical services provided by a tertiary hospital than that by secondary hospitals $(3.265>3.011, \mathrm{p}=0.04)$. However, when we looked at the five dimensions separately, the difference was only significant in the assurance dimension. 


\begin{tabular}{|c|c|c|}
\hline Characteristics & Variables & $\mathbf{N}(\%)$ \\
\hline \multirow[t]{2}{*}{ Gender } & Male & $434(54.7)$ \\
\hline & Female & $360(33.4)$ \\
\hline \multirow[t]{5}{*}{ Age group (years) } & $18-29$ & $239(30.1)$ \\
\hline & $30-39$ & 265 (33.4) \\
\hline & $40-49$ & $165(20.8)$ \\
\hline & $50-59$ & 92 (11.6) \\
\hline & $>60$ & $33(4.2)$ \\
\hline \multirow[t]{3}{*}{ Marital status } & Single & $237(29.8)$ \\
\hline & Married & $476(59.9)$ \\
\hline & $\begin{array}{l}\text { Divorced or } \\
\text { widowed }\end{array}$ & $81(10.2)$ \\
\hline \multirow[t]{4}{*}{ Educational level } & Illiterate & 209 (26.3) \\
\hline & Elementary & $202(25.4)$ \\
\hline & High school & 209 (26.3) \\
\hline & $\begin{array}{l}\text { Undergraduate } \\
\text { and above }\end{array}$ & $174(21.9)$ \\
\hline \multirow[t]{6}{*}{ Employment } & Self-employed & $194(24.4)$ \\
\hline & $\begin{array}{l}\text { Organisational } \\
\text { employed }\end{array}$ & $162(20.4)$ \\
\hline & $\begin{array}{l}\text { Daily labour or } \\
\text { unemployed }\end{array}$ & $132(16.6)$ \\
\hline & Farmer & $156(19.6)$ \\
\hline & Housewife & $87(11)$ \\
\hline & Others & $63(7.9)$ \\
\hline \multirow[t]{4}{*}{ Religion } & Orthodox & $650(81.9)$ \\
\hline & Catholic & $34(4.3)$ \\
\hline & Muslim & $93(11.7)$ \\
\hline & Protestant & $17(2.1)$ \\
\hline \multirow[t]{4}{*}{ Ethnicity } & Tigri & $653(82.2)$ \\
\hline & Amhara & $63(7.9)$ \\
\hline & Afar & $42(5.3)$ \\
\hline & Others & $36(4.5)$ \\
\hline \multirow[t]{2}{*}{ Residence } & Urban & $401(50.5)$ \\
\hline & Rural & $393(49.5)$ \\
\hline \multirow[t]{2}{*}{ Service sought } & Self & $544(68.5)$ \\
\hline & $\begin{array}{l}\text { Others (family/ } \\
\text { relatives) }\end{array}$ & $250(31.5)$ \\
\hline
\end{tabular}

\section{Association between sociodemographic characteristics and quality perception}

We explored the associations between sociodemographic variables and quality perceptions. There were significant differences in the quality scores between participants in different age groups, marital status, education level, employment status and residence (table 6). Respondents who were older, widowed, illiterate, farmer, retired or in the religious group of Orthodox were found to have a better perception of the quality service than others.
Table 3 Cronbach's alpha for the five dimensions of service quality

\begin{tabular}{lcll}
\hline Variables & $\begin{array}{c}\text { Number } \\
\text { of items }\end{array}$ & Mean (SD) & $\begin{array}{l}\text { Cronbach's } \\
\text { alpha }\end{array}$ \\
\hline Tangibility & 5 & $3.19(0.404)$ & 0.771 \\
Reliability & 5 & $2.81(0.563)$ & 0.768 \\
Responsiveness & 4 & $3.08(0.639)$ & 0.746 \\
Assurance & 6 & $2.87(0.609)$ & 0.760 \\
Empathy & 3 & $3.71(0.525)$ & 0.769 \\
Total & $\mathbf{2 3}$ & $\mathbf{3 . 1 3}(\mathbf{0 . 4 0 7 )}$ & $\mathbf{0 . 8 7 7}$ \\
\hline
\end{tabular}

\section{DISCUSSION}

Evaluating customers' perception of the service quality has become a fundamental practice for improving service delivery in all sectors as well as in the hospital pharmacies. ${ }^{22}$ Using the SERVQUAL instrument, we assessed outpatients' perception of the quality of pharmaceutical services in hospital pharmacies adopting APTS in Tigray, northern Ethiopia. The mean perception score of quality of the services provided at outpatient pharmacies was 3.1. Patients in the tertiary hospital showed a higher perception of the service quality compared with patients in secondary hospitals. Moreover, patients' demographic characteristics such as age, marital status, degree of education, employment and religion could affect their perceptions towards the quality of pharmaceutical services.

Overall, participants' perception of the pharmaceutical services was 3.1, out of a maximum score of 5 . This finding was better than the results generated in tertiary hospitals in northwestern Ethiopia before APTS, where patient satisfaction with outpatient pharmacy service was evaluated, and the overall mean score was only $2.48 .^{23}$ Similar to our results, the quality of hospital pharmacy services in southern Iran and eastern Saudi Arabia was also reported above average. ${ }^{1324}$ Considering the five quality dimensions, empathy got the highest score of 3.71 ; followed by tangible, 3.19 and responsiveness, 3.08. In contrast, reliability and assurance only got a score of less than 3 , which indicates a significant gap in quality service delivery.

A study conducted before the implementation of APTS at 17 hospitals showed that nearly half $(45.1 \%)$ of the patients were unsatisfied with the privacy services of the pharmacy. ${ }^{23}$ Therefore, APTS required every hospital with APTS to redesign the layout of its outpatient pharmacy to maintain patients' privacy. ${ }^{25}$ However, as some areas may have a low level of achievement, ${ }^{8}$ previous studies found that patients were dissatisfied in the privacy of the dispensing area in hospitals with APTS of eastern Ethiopia. ${ }^{1120}$ In our study, the highest perception of empathy was observed, which indicates that hospitals in Tigray may meet the APTS requirements of patients' privacy very well. Also, pharmacists in these pharmacies provided adequate care and attention to patients with courtesy and respect.

The dimension of reliability got the lowest mean score of 2.81, especially for 'the results of medication therapy' 
Table 4 Mean service quality scores on the five dimensions

\begin{tabular}{ll}
\hline Variables & Mean (SD) \\
\hline Tangibility & $3.19(0.41)$ \\
T1: The waiting area is clean and & $3.63(0.58)$ \\
comfortable &
\end{tabular}

T2: Inside of the pharmacy looks clean $3.64(0.55)$ and tidy

T3: The outpatient pharmacy is near to $3.01(0.80)$ your care services or easy to find

T4: Pharmacists are well dressed and $3.67(0.57)$
appear neat
$\begin{aligned} & \text { T5: Medication prescribed to you are } \\ & \text { available in the pharmacy }\end{aligned}$

\begin{tabular}{ll} 
Reliability & $2.81(0.56)$ \\
$\begin{array}{l}\text { R1: Pharmacy professional gave you } \\
\text { the results you can expect from your }\end{array}$ & $2.31(0.97)$ \\
medication therapy & \\
$\begin{array}{l}\text { R2: The medications dispensed to you } \\
\text { were of good quality }\end{array}$ & $3.18(0.98)$ \\
$\begin{array}{l}\text { R3: Cost of medication is fair } \\
\text { R4: Pharmacist shows }\end{array}$ & $2.43(0.97)$ \\
professionalism & $3.34(0.86)$ \\
$\begin{array}{l}\text { R5: Pharmacist works together } \\
\text { with your doctor to make sure the } \\
\text { medications are best for you }\end{array}$ & $2.82(0.97)$ \\
\hline
\end{tabular}

\begin{tabular}{ll} 
Responsiveness & $3.08(0.64)$ \\
\hline $\begin{array}{l}\text { P1: The pharmacy professional } \\
\text { answered your questions very well }\end{array}$ & $3.12(0.85)$ \\
$\begin{array}{l}\text { P2: The prescription medications were } \\
\text { issued promptly }\end{array}$ & $3.27(0.78)$ \\
$\begin{array}{l}\text { P3: The pharmacy professional spent } \\
\text { enough time with you }\end{array}$ & $2.61(0.82)$ \\
$\begin{array}{l}\text { P4: You didn't have to wait too long for } \\
\text { your prescription to be filled }\end{array}$ & $3.35(0.83)$ \\
$\begin{array}{l}\text { Assurance } \\
\text { A1: Pharmacy professional was careful } \\
\text { while supplying your medications }\end{array}$ & $\mathbf{2 . 8 7}(\mathbf{0 . 6 1})$ \\
\hline
\end{tabular}

A2: Pharmacist was confident about the $3.76(0.79)$ dispensed drugs

A3: The pharmacy professional's $\quad 3.41(0.79)$
instructions on how to take your
medication are clear

A4: The pharmacist gave you $2.20(0.92)$ information about proper storage of your medication

$\begin{array}{ll}\text { A5: The label on the medication } & 2.50(0.99) \\ \text { supplied to you is clear to read and } \\ \text { easy to understand }\end{array}$

Continued
Table 4 Continued

\begin{tabular}{ll}
\hline Variables & Mean (SD) \\
\hline $\begin{array}{l}\text { E2: Pharmacy staff showed you } \\
\text { courtesy and respect }\end{array}$ & $3.77(0.69)$ \\
$\begin{array}{l}\text { E3: The privacy was maintained during } \\
\text { your conversation with the pharmacist }\end{array}$ & $3.83(0.66)$ \\
\begin{tabular}{ll} 
Overall & $\mathbf{3 . 1 3 ( 0 . 4 0 )}$ \\
\hline
\end{tabular}
\end{tabular}

(R1), 'cost of medication' (R3) and 'pharmacist works together with doctor' (R5). The low perception of medication therapy can be affected by complex factors. As related to pharmacists, patient counselling is a crucial component for better therapeutic outcomes. ${ }^{26}$ However, on the one hand, pharmacists in Ethiopia focused primarily on dispensing medicines, and they were unable to deliver pharmaceutical service possibly due to lack of competency $^{20}$; on the other hand, Ethiopia has one of the lowest primary school enrolment rates and one of the highest illiteracy rates in the world, limited literacy of patients impeded understanding of proper medication use. ${ }^{27}$ Both two factors may lead to patients' low perception of medication therapy. Moreover, to provide quality pharmaceutical care, pharmacists should play a more active role in healthcare, working together with doctors, and even patients, to recommend and manage treatment. ${ }^{28}$ Low patients' perception of 'pharmacist works together with doctor' may also lead to a low perception of the results of the medication therapy. However, APTS may still contribute to significant improvements. Prior to the implementation of APTS, one study conducted in northwestern Ethiopia found that patients' perception of 'the results of your medication therapy' (R1) and 'pharmacist works together with doctor' (R5) was less than 2 out of $5 .^{20}$ The perception of fairness of medication's cost was the combining results of medicine price and patients' income, known as affordability. In Ethiopia, the affordability of medicines was always a significant constraint. A previous study found that least priced drugs were unaffordable for half of the standard treatments. ${ }^{5}$ Therefore, for service quality enhancement, hospitals need to encourage pharmacists to work with other health professionals to promote better pharmaceutical outcomes. At the same time, the government should make more efforts to improve the affordability of medicines.

The dimension of assurance also got a negative perception (2.87), especially for 'information about proper storage of your medication' (A4), 'the label on the medication' (A5) and 'pharmacist explained possible side effects' (A6). All the three statements (A4-6) are basic pharmaceutical practices of pharmacists. Many medicines require a special storage environment, such as away from heat, moisture and direct light. Improper storage of medicine may decrease its potency. For example, one study reported that improper storage of levothyroxine tablets led to patients presenting with refractory hypothyroidism. ${ }^{29}$ Clear information about side effects can help 
Table 5 Association between facility type and patients' perception of service quality

\begin{tabular}{|c|c|c|c|c|c|}
\hline Variables & Level of hospital & $\mathbf{N}$ & Mean (SD) & $\mathbf{t}$ & $P$ value \\
\hline \multirow[t]{2}{*}{ Tangibility } & Secondary & 399 & $3.125(0.405)$ & -4.659 & 0.330 \\
\hline & Tertiary & 395 & $3.257(0.393)$ & & \\
\hline Reliability & Tertiary & 395 & $2.902(0.521)$ & & \\
\hline Responsiveness & Secondary & 399 & 2.955 (0.652) & -5.989 & 0.241 \\
\hline \multirow[t]{2}{*}{ Assurance } & Secondary & 399 & $2.706(0.622)$ & -8.375 & 0.001 \\
\hline & Tertiary & 395 & $3.053(0.544)$ & & \\
\hline \multirow[t]{2}{*}{ Empathy } & Secondary & 399 & $3.543(0.494)$ & -9.881 & 0.457 \\
\hline & Tertiary & 395 & $3.891(0.498)$ & & \\
\hline Overall & Secondary & 399 & $3.011(0.424)$ & -8.833 & 0.043 \\
\hline
\end{tabular}

patients distinguish whether the side effects they were experiencing were normal or abnormal. If abnormal side effects were noticed, patients can contact the physicians in time. All this information needs to be provided to patients not only by oral instruction, but also through labels on the medicine which can help patients refer to at any time. As the final link between medication and patients, pharmacists should provide appropriate, understandable and relevant information to patients about their medication. ${ }^{27}$ However, based on our results, hospitals with APTS in Tigray have not done enough in this area. Maybe this is also the reason of low perception of 'pharmacist spending enough time with patient' (P3) in responsiveness. Therefore, to improve the pharmaceutical service for outpatients, the government needs to develop guidelines on information provided to patients and train the pharmacists to follow them.

In addition, statement of medicine availability (T5) in tangibility also showed a lot of room for improvement, with mean scores lower than 3. The problem of low availability of medicines has been reported before and after APTS implementation by other studies conducted elsewhere in Ethiopia. ${ }^{1125}$ Low availability of medicines in public hospitals enforced patients to purchase medication from private community pharmacies with high cost, which would increase patients' disease burden. Poor inventory management and absence of reliable suppliers (currently most just from pharmaceutical fund and supply agency of Ethiopia, referred as PFSA) were regarded as two main factors leading to this problem. ${ }^{23} 30$ To solve this problem, various procurement methods besides direct procurement from PFSA can be applied. Moreover, efficient inventory management methods can be used by hospitals. For example, hospitals can employ ABC (classifying medicines on the cost burden into always, better and control) and VEN classification (classifying medicines on their criticality into vital, essential and normal) to develop meaningful control over inventories. ${ }^{31}$
The level of the hospital was also a crucial factor affecting the patient's perception. In our study, patients had a higher perception score of the service quality provided by a tertiary hospital than secondary hospitals (3.265 $>3.011$, $\mathrm{p}=0.04$ ), but the difference was only significant in the assurance dimension. A higher level of perception of the assurance dimension required that pharmacists should be more professional and knowledgeable. In general, comparing with secondary hospitals, pharmacists in the tertiary hospital got a better education, which led to the above result. APTS has a uniform requirement for layout of pharmacy and processing of service. Therefore, the quality of pharmacy services provided by different hospitals had no significant difference, just considering the four dimensions except assurance. This finding suggested that to improve the pharmaceutical service quality of hospitals with APTS, managers should provide more training for pharmacists to enrich their knowledge. When expanding the APTS to primary hospitals, such kind of training would also be a priority.

Significant differences in quality perception were found among participants with different sociodemographic characteristics. Patients who were older, widowed, illiterate, farmer, retired and Orthodox reported a higher level of perception than others. This finding was following previous studies done in Ethiopia, ${ }^{20} 32$ which also indicated that those who were older, widowed, illiterate and farmer had higher perception of the quality of pharmaceutical services. The reason may be the uneducated and elderly patients had a lower expectation of pharmacy services, so they were over-rating it. ${ }^{20}$ But for the widowed patients, our result was contrary to another research in eastern Ethiopia, which showed that widowed or divorced patients were more likely dissatisfied with pharmacy services. ${ }^{11}$ The association between sociodemographic characteristics and the level of satisfaction was controversial. Studies conducted in Ethiopia (capital city, Addis Ababa), Malaysia and Korea indicated that there was no 
Table 6 Mean outpatient pharmaceutical service quality scores on demographic characteristics

\begin{tabular}{|c|c|c|c|c|c|c|}
\hline Characteristic & $\begin{array}{l}\text { Tangibility } \\
\text { Mean (SD) }\end{array}$ & $\begin{array}{l}\text { Reliability } \\
\text { Mean (SD) }\end{array}$ & $\begin{array}{l}\text { Responsiveness } \\
\text { Mean (SD) }\end{array}$ & $\begin{array}{l}\text { Assurance } \\
\text { Mean (SD) }\end{array}$ & $\begin{array}{l}\text { Empathy } \\
\text { Mean (SD) }\end{array}$ & $\begin{array}{l}\text { Total } \\
\text { Mean (SD) }\end{array}$ \\
\hline \multicolumn{7}{|l|}{ Gender } \\
\hline Male & $3.19(0.40)$ & $2.80(0.55)$ & $3.09(0.66)$ & $2.87(0.63)$ & $3.71(0.53)$ & $3.07(0.43)$ \\
\hline Female & $3.19(0.41)$ & $2.83(0.58)$ & $3.09(0.61)$ & $2.89(0.59)$ & $3.72(0.52)$ & $3.08(0.42)$ \\
\hline$P$ value & 0.531 & 0.227 & 0.103 & 0.694 & 0.988 & 0.415 \\
\hline \multicolumn{7}{|l|}{ Age group } \\
\hline $18-29$ & $3.12(0.39)$ & $2.75(0.54)$ & $2.96(0.58)$ & $2.76(0.56)$ & $3.60(0.49)$ & $2.98(0.38)$ \\
\hline $30-39$ & $3.17(0.41)$ & $2.74(0.56)$ & $3.01(0.64)$ & $2.84(0.57)$ & $3.71(0.54)$ & $3.03(0.42)$ \\
\hline $40-49$ & $3.23(0.41)$ & $2.89(0.58)$ & $3.19(0.68)$ & $2.91(0.65)$ & $3.78(0.54)$ & $3.14(0.46)$ \\
\hline $50-59$ & $3.32(0.39)$ & $2.98(0.56)$ & $3.33(0.60)$ & $3.10(0.61)$ & $3.87(0.49)$ & $3.26(0.41)$ \\
\hline$>60$ & $3.36(0.36)$ & $3.02(0.56)$ & $3.52(0.52)$ & $3.27(0.72)$ & $3.89(0.43)$ & $3.36(0.41)$ \\
\hline$P$ value & 0.001 & 0.001 & 0.001 & 0.001 & 0.001 & 0.001 \\
\hline \multicolumn{7}{|l|}{ Marital status } \\
\hline Single & $3.10(0.38)$ & $2.73(0.54)$ & $3.01(0.55)$ & $2.82(0.55)$ & $3.61(0.52)$ & $3.00(0.38)$ \\
\hline Married & $3.23(0.41)$ & $2.84(0.55)$ & $3.12(0.66)$ & $2.91(0.63)$ & $3.76(0.53)$ & $3.11(0.43)$ \\
\hline Divorced & $3.22(0.39)$ & $2.76(0.70)$ & $2.98(0.73)$ & $2.72(0.71)$ & $3.73(0.52)$ & $3.01(0.49)$ \\
\hline Widowed & $3.23(0.43)$ & $3.09(0.53)$ & $3.31(0.77)$ & $3.02(0.54)$ & $3.88(0.51)$ & $3.24(0.44)$ \\
\hline$P$ value & 0.001 & 0.003 & 0.018 & 0.033 & 0.002 & 0.001 \\
\hline \multicolumn{7}{|l|}{ Education } \\
\hline Illiterate & $3.44(0.32)$ & $3.21(0.45)$ & $3.65(0.42)$ & $3.41(0.51)$ & $4.03(0.42)$ & $3.49(0.29)$ \\
\hline Elementary & $3.21(0.38)$ & $2.80(0.53)$ & 3.09 (0.52) & $2.85(0.53)$ & $3.72(0.47)$ & $3.09(0.34)$ \\
\hline High school & $3.13(0.39)$ & $2.72(0.51)$ & $2.97(0.54)$ & $2.73(0.47)$ & $3.65(0.52)$ & $2.98(0.32)$ \\
\hline Graduated & $2.94(0.37)$ & $2.47(0.51)$ & $2.56(0.57)$ & $2.45(0.50)$ & $3.41(0.50)$ & $2.71(0.34)$ \\
\hline$P$ value & 0.001 & 0.001 & 0.001 & 0.001 & 0.001 & 0.001 \\
\hline \multicolumn{7}{|l|}{ Employment } \\
\hline Self-employed & $3.12(0.40)$ & $2.75(0.52)$ & $2.97(0.64)$ & $2.79(0.58)$ & $3.63(0.53)$ & $2.99(0.38)$ \\
\hline Employed & $2.97(0.37)$ & $2.53(0.51)$ & $2.69(0.55)$ & $2.53(0.45)$ & $3.44(0.50)$ & $2.77(0.33)$ \\
\hline Daily labour & $3.14(0.33)$ & $2.71(0.50)$ & $3.13(0.51)$ & $2.78(0.51)$ & $3.67(0.47)$ & $3.02(0.32)$ \\
\hline Farmer & $3.51(0.32)$ & $3.16(0.50)$ & $3.52(0.52)$ & $3.32(0.58)$ & $4.05(0.39)$ & $3.46(0.34)$ \\
\hline Housewife & $3.25(0.34)$ & $2.95(0.50)$ & $3.20(0.49)$ & $3.04(0.51)$ & $3.87(0.49)$ & $3.20(0.34)$ \\
\hline Others & $3.21(0.41)$ & $2.91(0.68)$ & $3.15(0.80)$ & $2.93(0.73)$ & $3.76(0.53)$ & $3.13(0.51)$ \\
\hline$P$ value & 0.001 & 0.001 & 0.001 & 0.001 & 0.001 & 0.001 \\
\hline \multicolumn{7}{|l|}{ Religion } \\
\hline Orthodox & $3.20(0.41)$ & $2.82(0.56)$ & $3.11(0.63)$ & $2.90(0.62)$ & $3.72(0.53)$ & $3.09(0.43)$ \\
\hline Catholic & $3.04(0.37)$ & $2.62(0.47)$ & $2.81(0.71)$ & $2.61(0.50)$ & $3.66(0.44)$ & $2.88(0.38)$ \\
\hline Muslim & $3.21(0.40)$ & $2.89(0.59)$ & $3.12(0.68)$ & $2.84(0.60)$ & $3.74(0.56)$ & $2.10(0.43)$ \\
\hline Protestant & $3.00(0.34)$ & $2.62(0.64)$ & $2.59(0.48)$ & $2.59(0.51)$ & $3.45(0.42)$ & $2.80(0.32)$ \\
\hline$P$ value & 0.028 & 0.056 & 0.001 & 0.008 & 0.169 & 0.001 \\
\hline \multicolumn{7}{|l|}{ Ethnicity } \\
\hline Tigri & $3.18(0.41)$ & $2.81(0.56)$ & $3.08(0.64)$ & $2.88(0.61)$ & $3.70(0.53)$ & $3.07(0.43)$ \\
\hline Amhara & $3.18(0.40)$ & $2.75(0.60)$ & 3.09 (0.59) & $2.84(0.58)$ & $3.70(0.53)$ & $3.05(0.39)$ \\
\hline Erob & $3.19(0.33)$ & $2.69(0.45)$ & $2.90(0.74)$ & $2.72(0.48)$ & $3.73(0.43)$ & $2.98(0.38)$ \\
\hline Afar & $3.33(0.37)$ & $3.02(0.61)$ & $3.28(0.70)$ & $3.01(0.65)$ & $3.90(0.47)$ & $3.24(0.45)$ \\
\hline Others & $3.22(0.38)$ & $2.73(0.52)$ & $3.05(0.61)$ & $2.89(0.62)$ & $3.88(0.40)$ & $2.08(0.41)$ \\
\hline$P$ value & 0.263 & 0.088 & 0.196 & 0.436 & 0.135 & 0.087 \\
\hline
\end{tabular}




\begin{tabular}{lcccccc}
\hline Table 6 Continued & & & & & \\
\hline Characteristic & $\begin{array}{l}\text { Tangibility } \\
\text { Mean (SD) }\end{array}$ & $\begin{array}{l}\text { Reliability } \\
\text { Mean (SD) }\end{array}$ & $\begin{array}{l}\text { Responsiveness } \\
\text { Mean (SD) }\end{array}$ & $\begin{array}{l}\text { Assurance } \\
\text { Mean (SD) }\end{array}$ & $\begin{array}{l}\text { Empathy } \\
\text { Mean (SD) }\end{array}$ & $\begin{array}{l}\text { Total } \\
\text { Mean (SD) }\end{array}$ \\
\hline Residence & & & & & \\
Urban & $3.03(0.38)$ & $2.64(0.56)$ & $2.82(0.62)$ & $3.66(0.55)$ & $3.52(0.51)$ & $2.88(0.38)$ \\
Rural & $3.36(0.36)$ & $2.99(0.51)$ & $3.36(0.54)$ & $3.10(0.59)$ & $3.92(0.47)$ & $3.28(0.37)$ \\
P value & $\mathbf{0 . 5 2 2}$ & $\mathbf{0 . 4 0 0}$ & $\mathbf{0 . 4 0 0}$ & $\mathbf{0 . 0 9 7}$ & $\mathbf{0 . 0 0 2}$ \\
Service sought for & & & & $2.84(0.63)$ & $3.67(0.53)$ & $3.05(0.44)$ \\
Self & $3.17(0.41)$ & $2.80(0.58)$ & $3.06(0.66)$ & $2.96(0.56)$ & $3.82(0.50)$ & $3.14(0.39)$ \\
Others & $3.24(0.39)$ & $2.84(0.53)$ & $3.15(0.60)$ & $\mathbf{0 . 0 4 9}$ & $\mathbf{0 . 4 4 6}$
\end{tabular}

$\mathrm{P}<0.05$ was considered statistically significant.

significant association between the level of satisfaction and respondents' gender, age or educational status. ${ }^{32-34}$

This study has several limitations. First, the generalisability of the results might be limited since it was only conducted in one region of Ethiopia. However, the sample size of this survey was reasonably large, and respondents with different demographic and socioeconomic features were sampled, which might help display the actual picture in Tigray. Second, the cross-sectional study design by itself has limited ability to confirm the causality of different variables. In the future, other research methods need to be used to dig the deep-rooted reasons for the perception of the quality of pharmaceutical services.

\section{CONCLUSIONS}

The perception of most of the patients toward the quality of pharmaceutical services of outpatient pharmacies in hospitals with APTS was positive. However, perception of assurance and reliability of pharmaceutical services was suboptimal. In addition, the low availability of medicine was also negatively perceived. Therefore, to further improve the service quality, we recommend the following: (1) managers should provide more training for pharmacists to strengthen their professional knowledge and encourage them to cooperate with other professionals; (2) the government needs to develop guidelines on information provided to patients and train the pharmacists to follow them; (3) hospitals can apply various procurement methods besides direct procurement from PFSA and efficient inventory management methods. For future research, a theoretical framework can be developed to delineate more variables in the patient perception of a service quality model.

Acknowledgements The authors thank Xi'an Jiaotong University Health Science/ School of Pharmacy, TRHB, patients, data collectors, management offices and hospitals for their help in completing this project.

Contributors DGK and CY-conceptualisation. DGK, AKA and CY-methodology. CY, DGK, CX, AKA and SH—software. CY, DGK, AKA and CX-formal analysis. DGK and AKA-investigation. CY, DGK, CX, SH and YF-resources. CY, DGK, CX, SH, AKA and YF-data curation. CY, DGK, AKA and YF-writing (original draft preparation).
CY, DGK, CX, SH, AKA, KH and YF—writing (review and editing). CY—visualisation and supervision. CY, DGK and YF_project administration. CY-funding acquisition.

Funding This work is supported by the Fundamental Research Funds for the Central Universities, and the Department of Science and Technology of Shaanxi Province (2020SF-279).

Competing interests None declared.

Patient and public involvement Patients and/or the public were not involved in the design, or conduct, or reporting, or dissemination plans of this research.

Patient consent for publication Not required.

Ethics approval The study was approved by the Ethics Review Committee of Xi'an Jiaotong University Health Science Centre (Xi'an, China). Moreover, the permission to conduct this study was also obtained from the Health Research Ethics Review Committee at Mekelle University, College of Health Sciences and Tigray Regional Health Bureau Research team, and all the participating hospitals. Written and verbal consent was obtained from each participant, and the data were analysed anonymously.

Provenance and peer review Not commissioned; externally peer reviewed.

Data availability statement No data are available. № additional data available.

Open access This is an open access article distributed in accordance with the Creative Commons Attribution Non Commercial (CC BY-NC 4.0) license, which permits others to distribute, remix, adapt, build upon this work non-commercially, and license their derivative works on different terms, provided the original work is properly cited, appropriate credit is given, any changes made indicated, and the use is non-commercial. See: http://creativecommons.org/licenses/by-nc/4.0/.

ORCID iD

Caijun Yang http://orcid.org/0000-0001-5127-7075

\section{REFERENCES}

1 Allemann SS, van Mil JWF, Botermann L, et al. Pharmaceutical care: the PCNE definition 2013. Int J Clin Pharm 2014;36:544-55.

2 Teshale C, Hussein J, Mussa S. Assessment of the quality of pharmaceutical service in Jimma zone, Oromia regional state, South West Ethiopia. IJPTP 2014;5:1-6.

3 EMOH. Ethiopia-Health sector developmental Plan-iv-2010-2015. Ethiopia Ministry of health strategic plan, 2010.

$4 \mathrm{EMOH}$. Ethiopia-health-system-transformation-plan 2015/16 2019/20. 1. Ethiopia Ministry of health strategic plan, 2015.

5 Mensa M, Ayele A, Wogayehu B. Assessment of Auditable pharmaceutical transactions at public hospitals in Gamo Gofa, southern Ethiopia. A comparative cross-sectional study. bioRxiv 2018.

6 World Health Organization. Promoting rational use of medicines: core components. Geneva: World Health Organization, 2002.

7 Wogayehu B, Chisha Y, Tekabe Be'emnetu, et al. A cross sectional comparison of drug use indicators using who methodology in primary level hospitals participating in an Auditable pharmaceutical 
transactions and services program versus non-APTS primary hospitals in southern Ethiopia. PLoS One 2019;14:e0223523.

8 SIPS. Transforming pharmaceutical services in Ethiopia through Auditable pharmaceutical transactions and services report. systems for improved access to pharmaceuticals and services, 2017.

9 Farris KB, Kirking DM. Assessing the quality of pharmaceutical care. II. Application of concepts of quality assessment from medical care. Ann Pharmacother 1993;27:215-23.

10 Saddique AA. Development of clinical pharmacy services at King Khalid university hospital and its impact on the quality of healthcare provided. Saudi Pharm J 2012;20:273-7.

11 Nigussie S, Edessa D. The extent and reasons for Dissatisfaction from outpatients provided with pharmacy services at two public hospitals in eastern Ethiopia. Front Pharmacol 2018;9:1132.

13 Al Fraihi KJ, Latif SA. Evaluation of outpatient service quality in eastern Saudi Arabia. patient's expectations and perceptions. Saudi Med J 2016;37:420-8.

14 Jebraeily M, Rahimi B, Zare Fazlollahi Z, et al. Using SERVQUAL model to assess Hospital information system service quality. Hormozgan Medical Journal 2019;23:e86977.

15 Parasuraman A, Zeithaml VA, Berry LL. A conceptual model of service quality and its implications for future research. J Mark 1985:49:41-50.

16 Grönroos C. A service quality model and its marketing implications. Eur J Mark 1984;18:36-44.

17 Yousapronpaiboon K, C. Johnson W. Measuring Hospital out-patient service quality in Thailand. Leadersh Health Serv 2013;26:338-55.

18 Imran M, Iqbal J, Saleem F. Clients satisfaction with the provision of services of an out-patient pharmacy at a tertiary care hospital in Lahore, Punjab, Pakistan. Indo Am J pharm 2018;5:92-7.

19 Li M, Lowrie DB, Huang C-Y, et al. Evaluating patients' perception of service quality at hospitals in nine Chinese cities by use of the ServQual scale. Asian Pac J Trop Biomed 2015;5:497-504.

20 Surur AS, Teni FS, Girmay G, et al. Satisfaction of clients with the services of an outpatient pharmacy at a university hospital in northwestern Ethiopia: a cross-sectional study. BMC Health Serv Res 2015;15:229.

21 lacobucci D, Duhachek A. Advancing alpha: measuring reliability with confidence. J Consum Psychol 2003;13:478-87.

22 Sivakumar M. Assessment of service quality in multi speciality hospitals with reference to Madurai. Int J Bus Adm Res Rev 2014;1:170-4.

23 Tadeg EE H, Geremew E, Adinew A. Auditable pharmaceutical transactions and services (APTS): findings of the baseline assessment at federal, Addis Ababa, and teaching hospitals. submitted to the US agency for international development by the systems for improved access to pharmaceuticals and services (SIAPS) program. Arlington VA: Management Sciences for Health, 2014.

24 Aghamolaei T, Eftekhaari TE, Rafati S, et al. Service quality assessment of a referral hospital in southern Iran with SERVQUAL technique: patients' perspective. BMC Health Serv Res 2014;14:322.

25 Fenta TG, Teshome D, Gulelat B. Outcomes of Auditable pharmaceutical transactions and services (APTS) implementation: assessment report. submitted to the federal Ministry of health (FMOH), Ethiopian pharmaceutical association (EPA), and systems for improved access to pharmaceuticals and services (SIAPS. Addis Ababa: FMOH, EPA, and SIAPS, 2016.

26 El-Dahiyat F, Curley LE, Babar Z-U-D. A survey study to measure the practice of patient counselling and other community pharmacy services in Jordan. Int J Bus Adm Res Rev 2019;10:133-9.

27 Wado TE, Gunasekaran T, Dhanaraju MD. Pharmacist-patient communication barriers in dispensing practice: a descriptive study in Adama hospital medical College, Adama City, Oromia regional state, Ethiopia. J Pharm Health Serv Res 2015;6:219-24.

28 Hall PD, Fish H, McBane S, et al. The report of the 2018-2019 professional Affairs standing Committee: the role of educators in pharmacy practice transformation. Am J Pharm Educ 2019;83:7596-63.

29 Benvenga S, Papi G, Antonelli A. Refractory hypothyroidism due to improper storage of levothyroxine tablets. Front Endocrinol 2017:8:155

30 Kefale AT, Shebo HH. Availability of essential medicines and pharmaceutical inventory management practice at health centers of Adama town, Ethiopia. BMC Health Serv Res 2019;19:254.

31 Mohammed SA, Workneh BD. Critical analysis of pharmaceuticals inventory management using the ABC-VEN matrix in Dessie referral Hospital, Ethiopia. Integr Pharm Res Pract 2020;9:113-25.

32 Teshome Kefale A, Hagos Atsebah G, Ayele Mega T. Clients' perception and satisfaction toward service provided by pharmacy professionals at a teaching hospital in Ethiopia. Integr Pharm Res Pract 2016;5:85-94.

33 Ayalew MB, Taye K, Asfaw D, et al. Patients'/clients' expectation toward and satisfaction from pharmacy services. J Res Pharm Pract 2017;6:21-6.

34 Lee S, Godwin OP, Kim K, et al. Predictive factors of patient satisfaction with pharmacy services in South Korea: a crosssectional study of national level data. PLoS One 2015;10:e0142269.

35 Nagashekara M, Sze-Nee N, David M. Patient satisfaction in general, intervention and cognitive services among retail pharmacies in Kota Kinabalu, Malaysia. Int Res J Pharm 2012;3:141-4. 